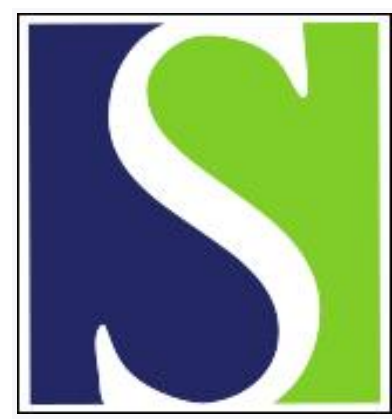

Scand J Work Environ Health 2000;26(4):306-316

https://doi.org/10.5271/sjweh.547

Issue date: Aug 2000

Neuroendocrine reactivity and recovery from work with different physical and mental demands

by Sluiter JK, Frings-Dresen MHW, van der Beek AJ, Meijman TF, Heisterkamp SH

The following articles refer to this text: 2003;29(3):171-188;

2004;30(2):129-138; 2009;35(3):188-192

Key terms: adrenaline; cortisol; mental work; mental-physical work; noradrenaline; physical work

This article in PubMed: www.ncbi.nlm.nih.gov/pubmed/10994796 


\title{
Neuroendocrine reactivity and recovery from work with different physical and mental demands
}

\author{
by Judith K Sluiter, PhD, ${ }^{1}$ Monique HW Frings-Dresen, PhD, ${ }^{1}$ Allard J van der Beek, PhD, ${ }^{1}$ Theo FMeij- \\ man, PhD, ${ }^{2}$ Siem H Heisterkamp, PhD
}

\begin{abstract}
Sluiter JK, Frings-Dresen MHW, van der Beek AJ, Meijman TF, Heisterkamp SH. Neuroendocrine reactivity and recovery from work with different physical and mental demands. Scand J Work Environ Health 2000;26(4):306316.
\end{abstract}

\begin{abstract}
Objectives The purpose of this study was to examine the extent to which the type or nature (physical, mental or mixed mental and physical) of work and work characteristics is related to the course of neuroendocrine reactivity and recovery from work.

Methods Neuroendocrine reactivity and recovery were studied by measuring the urinary excretion of adrenaline, noradrenaline, and cortisol during and after 3 workdays, 1 consecutive day off, and a baseline day. The assessment was made in 3 groups of Dutch male workers $(\mathrm{N}=60)$ who differed in the nature (mental, physical, and combined mental and physical demands) of their work. Multilevel analyses were performed to fit linear mixed-effects models for each hormone.

Results Main or interaction effects with time of day were found between the workers in combined mental and physical work and the 2 other groups of workers for cortisol, adrenaline, and noradrenaline excretion. In addition, the baseline levels of the 3 hormones were higher in the workers with combined mental and physical work when compared with the other 2 groups. The excretion rates during the workdays were higher than those on the day off, but a trend towards mobilizing less activity was found from the 1 st to the 3 rd workday. Job demands were negatively related to cortisol excretion. Job control and social demands at work did not affect the excretion rates of the hormones.

Conclusions Unfavorable effects on cortisol and adrenaline reactivity or recovery was found for workers with combined mental and physical demands when compared with workers doing mainly mental or mainly physical work. The results of the present study are in accordance with the cognitive activation theory and the allostatic load model.
\end{abstract}

Key terms adrenaline, cortisol, mental work, mental-physical work, noradrenaline, physical work.

High work load seems to be a problem in many branches of industry, although the nature of work may account for some differences in work load among workers. Three of the 4 most common work-related health problems of workers in the European Union are stress, overall fatigue, and muscular pain (1).

Most studies concerning the work-relatedness of fatigue, need for recovery, stress symptoms, and temporary psychological overload use self-reported information. On the other hand, psychophysiological measurements can play a relevant role in the assessment of the interaction between work, stress, and health (2-4), because a change in activation level in bodily systems is needed in every situation in which there is a difference between the actual value of a certain homeostatic variable and the value of that variable needed to be able to cope with the situation (5). Increased activation will persist until the balance between the 2 is re-established. Persistence of the neuroendocrine reactivity level, despite the cessation of the situational stressor, has been called sustained activation (6), and the return to the actual value has been labeled unwinding (7). Catecholamine and cortisol reactivity during work is a normal and essential neuroendocrine response enabling contextual coping, and

1 Coronel Institute for Occupational and Environmental Health, Academic Medical Center, University of Amsterdam, Amsterdam, The Netherlands.

2 Experimental and Work Psychology, University of Groningen, Groningen, The Netherlands.

3 Department of Clinical Epidemiology and Biostatistics, Academic Medical Center, University of Amsterdam, Amsterdam, The Netherlands.

Reprints requests to: Dr Judith Sluiter, Coronel Institute for Occupational and Environmental Health, Academic Medical Center, University of Amsterdam, PO Box 22700, 1100 DE Amsterdam, The Netherlands. [E-mail: j.sluiter@amc.uva.nl] 
neuroendocrine recovery from occupationally induced exertion during and after work is considered essential to the prevention of work-related disorders. It has been hypothesized that repeated insufficient recovery from workrelated neuroendocrine reactivity may start a vicious circle in which extra effort must be exerted in every new work period to rebalance the suboptimal psychophysiological state of sustained activation and to prevent performance breakdown $(6,7)$. In turn, this extra effort increases the risk of insufficient recovery. Iterations of a suboptimal psychophysiological state and corresponding poor recovery and unwinding are thought to be responsible for the development of health complaints in the long run $(6,8,9)$.

Sustained activation of the catecholamines during the 1 st (evening) hours after work has been assessed in urine by Frankenhaeuser et al (2), Rissler $(10,11)$, Meijman et al (7), and Kuiper et al (12), among others. However, the measurements performed in these studies did not allow the authors to assess a longer course of neuroendocrine recovery. Not many occupational studies have assessed the sustained activation of urinary cortisol, and the results were not conclusive $(2,13,14)$. A systematic review of neuroendocrine reactivity and recovery after different types of tasks found a lack of studies that assessed the course of recovery in relation to different job demands (15).

To assess the course of neuroendocrine reactivity and recovery, we used a conceptual categorization in recovery time, as proposed previously (15). Because "worklife" is generally organized into fixed time schedules, this categorization distinguishes reactivity and micro recovery during workhours, meso- and meta-recovery for short-term and longer-term recovery after work and the time between workdays.

The nature of the workers' main task or activity has been defined as the most dominant work characteristic in which jobs differ (16). The demands that tasks or activities place on people can be categorized as mental, physical, or a combination of mental and physical. Because psychosocial work characteristics are also known to influence the perceived work load and health status of the worker, the types and levels of psychological demands (job demands and decision latitude) and social demands (relation to superiors or colleagues) are also of interest (17-19). Frankenhaeuser et al (20) found that both catecholamine and cortisol excretion were significantly elevated in a low-control situation, while cortisol levels were low or depressed in the high-control situation. This finding contrasted with the elevated levels of the catecholamines. Studies of different occupations for example, insurance company workers (10), prison staff (21), nurses (22), physicians (23), driving examiners (7), and engineers (11) — have found these psychosocial factors to be associated mainly with the level of adrenaline reactivity during work, possibly influencing catecholamine recovery after work as well.

In order to study the differential neuroendocrine reactivity and recovery in relation to work characteristics, we compared 3 groups of male workers. The main objective was to determine the extent to which the nature of work (mental, physical, and the combination of both types of demand) and psychosocial work characteristics (job demands, job control, and social demands) are related to the course of urinary reactivity and the recovery of adrenaline, noradrenaline, and cortisol. It was hypothesized that, irrespective of the levels the psychosocial work characteristics, a difference exists between the 3 groups in both neuroendocrine reactivity and recovery from work. A 2nd hypothesis, concerning the work characteristics, was that it is expected for job demands to be related to adrenaline reactivity and recovery, while job control is expected to be related to cortisol reactivity and recovery. This hypothesis was studied for 60 male workers in the natural work environment in The Netherlands.

\section{Subjects, material and methods}

\section{Study sample}

Sixty male workers were randomly selected from the involved companies to be part of 1 of 3 groups that performed either mainly mental, mainly physical, or combined mental and physical tasks during their daily work. The inclusion criteria were (i) a minimum of 1 year's experience in the job and (ii) performance of normal work routines during the time of the measurements. The mental group ( $\mathrm{N}=20)$ consisted of (middle) management and supervisors from a flower auction and foremen from a construction company. The physical group $(\mathrm{N}=20)$ included manual flower transport workers from a flower auction, construction workers, and garbage collectors. The combined mental-physical group $(\mathrm{N}=20)$ included male nurses and drivers working for a municipal ambulance service. All the subjects gave their informed consent, and all the measurements took place between November 1997 and November 1998.

\section{Measurements of demographic variables and psychosocial work characteristics}

Data on demographics (age, body weight, body height, years of experience on the job) and psychosocial work characteristics (job demands, job control, social demands) were gathered with a self-administered questionnaire. Some questions were adapted for the populations in this study and others were taken from existing questionnaires. The ad-hoc questions asked for details of the workers' personal life, work experience, and some aspects of psychosocial work characteristics. The mean age of all the 
Table 1. Mean scores of the scales for the psychosocial work characteristics per group of workers (higher scores reflect more unfavorable work characteristics).

\begin{tabular}{|c|c|c|c|c|c|c|}
\hline \multirow[t]{2}{*}{ Group } & \multicolumn{2}{|c|}{$\begin{array}{l}\text { Job } \\
\text { demands }\end{array}$} & \multicolumn{2}{|c|}{$\begin{array}{l}\text { Job } \\
\text { control }\end{array}$} & \multicolumn{2}{|c|}{$\begin{array}{c}\text { Social } \\
\text { demands }\end{array}$} \\
\hline & $\begin{array}{c}\text { Mean } \\
(\%)\end{array}$ & $\begin{array}{c}\text { Range } \\
(\%)\end{array}$ & $\begin{array}{c}\text { Mean } \\
(\%)\end{array}$ & $\begin{array}{l}\text { Range } \\
(\%)\end{array}$ & $\begin{array}{c}\text { Mean } \\
(\%)\end{array}$ & $\begin{array}{c}\text { Range } \\
(\%)\end{array}$ \\
\hline Mental work & 56.4 & $33-85$ & 29.0 & $4-49$ & 21.9 & $4-52$ \\
\hline $\begin{array}{l}\text { Mixed mental and } \\
\text { physical work }\end{array}$ & 39.7 & $24-67$ & 67.4 & $46-79$ & 32.2 & $11-65$ \\
\hline Physical work & 43.8 & $27-70$ & 62.0 & $16-85$ & 29.5 & $0-63$ \\
\hline
\end{tabular}

workers was 39 (range 25-55) years, and their average body mass index (BMI) was 25.3 (range 17.6-34.4) kg/ $\mathrm{m}^{2}$. On the average, they had worked 10.4 (range 1-26) years with their companies. No differences between the 3 groups were notable for these variables (F-test: $\mathrm{P}=0.129,0.941$, and 0.237 , respectively). Data on work characteristics were gathered for 59 subjects. Work characteristics were operationalized in terms of job demands, job control, and social demands. Job demands were reflected by a validated Dutch 11-item scale of workpace and amount of work (Cronbach's alpha 0.88), which is part of the Questionnaire on Perception and Judgement of Work (24). Job control was reflected by a 3-item scale on break control and influence on work (Cronbach's alpha 0.94), an 11-item validated scale on autonomy (Cronbach's alpha 0.90), and an 8-item validated scale on participation in work (Cronbach's alpha 0.85), the last 2 scales also being part of the Questionnaire on Perception and Judgement of Work. Social demands were reflected by 2 validated 9-item scales of the Questionnaire on Perception and Judgement of Work, one of which concerned the relation with direct superiors (Cronbach's alpha 0.88 ) and the 2 nd the relation with colleagues (Cronbach's alpha 0.86). In all the questions on work characteristics, the subjects had to make a choice between never, sometimes, often, or always. All the answers to the work characteristic questions were recoded from never $=0$ points, to always $=3$ points. All the items were asked or recoded in such a way that a higher score meant more unfavorable work characteristics. For job demands, the sum score of the scale for workpace and amount of work was calculated, and the percentage score of the maximal possible sum score was established. For job control, the sum score was calculated from the 3 separate scale scores after the reliability of the combined "job control" scale had been assessed (Cronbach's alpha 0.80 ). The percentage score of the maximal possible sum score for the jobcontrol scale was then calculated. For social demands, the sum score and percentage score of the 2 relation scale scores was calculated after the reliability of the combined social-demands scale had been assessed (Cronbach's alpha $=0.62$ ).
The mean and range of the scores on the 3 psychosocial work characteristic scales are shown in table 1 for the 3 groups. There was a significant difference between the 3 groups in job demands and job control (F-test: $\mathrm{P}=0.001$ and 0.000 , respectively). A marginally significant difference in social demands was found between the 3 groups ( $\mathrm{F}$-test: $\mathrm{P}=0.096$ ).

A significant negative relationship was found for job demands and job control $(r=-0.30, P=0.022)$; this finding indicated more control over the job if the demands were higher. In addition, a positive significant relationship between job control and social demands was found $(r=0.45, P=0.000)$; it indicated less favorable social relations with superiors and colleagues if less control over the job was experienced.

\section{Observational measurements}

Observations were performed in order to assess the expected differences in the nature of the work among the 3 groups. All the subjects were observed in real time by means of TRAC (task recording and analysis on computer) (25) during 1 workday in order to assess the tasks and physical activities they performed. In addition, the frequencies of manually handling (ie, lifting, lowering, carrying, pushing, or pulling) material weight $>10$ kilograms in the mental group and $>25$ kilograms in the other 2 groups were observed. This difference in observation between the mental group and the other 2 groups was necessary because no loads over 25 kilograms are usually handled in jobs with mental demands only. The mean percentage worktime for the activities standing, sitting, and walking is shown in figure 1 for each group of workers.

A significant difference was found between the 3 groups for sitting, standing, and walking (all $\mathrm{P}=0.000$ ) in the expected direction, indicating more sitting and less standing and walking in the mental group compared with the 2 other groups. In addition, a significant difference between the mental and the other groups was found in the expected direction for the frequency of the manual handling of materials weighing $>10 \mathrm{~kg}$ in the mental group [mean 4 (SD 7.3)] and $>25 \mathrm{~kg}$ in the mental-physical group and physical group [mean 51 (SD 13.1) and 381 (SD 223.5), respectively] during a workday $(\mathrm{P}=0.000)$. In addition, more manual materials handling was found during the workday in the combined mentalphysical group than the mental group.

\section{Neuroendocrine measurements}

The urine concentrations of the hormones adrenaline, noradrenaline, and cortisol were determined. Urine was collected for 5 consecutive days (ie, 3 workdays and 2 days off work). This protocol allowed measurements of the within-subject reactivity during 3 workdays, the course of recovery from work during 3 evenings and 
nights after the workdays, a day off work, and baseline concentrations of the 3 hormones. The 5 th day was considered the baseline. To be able to compare the 3 groups of workers and to control for time of day (circadian rhythmicity), urine samples were collected at 6 fixed points in time during the day. These points were 0700,1100 , $1400,1700,2000$, and 2300. To remind the workers of the sample times, they were given "buzzers". At the 6 points of time, the buzzers were activated by the researchers.

Because of the real life character of the study, it was decided not to restrict the subjects in terms of behavioral habits. However, data on the consumption of coffee, tea, alcohol, nicotine, and medicine during all 5 days were collected so that we could check for differences between the 3 groups of workers. No significant difference was found for the number of smokers in the 3 groups (chi square: $\mathrm{P}=0.111$ ) nor for the number of subjects that consumed more than 15 glasses of alcohol per week (chi square: $\mathrm{P}=0.318$ ). No differences were found in the number of subjects that consumed more than 3 caffeinated drinks per day (chi square: $\mathrm{P}=0.286$ ) either, nor were there any differences in medication intake. Furthermore, the subjects did not report any emotional events, such as a quarrel or other traumatic incident.

All the times of urination were recorded and all the samples were collected in different jars containing 0.7 grams of citric acid. After collection, the jars were kept as cold as possible until further preparation, started within 24 hours, as described by Sluiter et al (14). All the neuroendocrine data on the 40 subjects in the mental and combined mental-physical groups were gathered. In the physical group neuroendocrine data were collected for 19 subjects.

\section{Data analysis and statistics}

All the preparatory data handling and calculations were performed with the Statistical Package for the Social
Sciences for Windows 7.5. In all the analyses, the differences were accepted as significant at $\mathrm{P}<0.05$.

The urinary concentrations (nanograms/milliliter) were multiplied by the volume of the corresponding urine sample (milliliters). This amount (nanograms) was divided by the period of time (minutes) between the urination sample and the previous urination to obtain the mean excretion rate for that period (nanograms/minute).

Multivariate multilevel analyses were performed using the nlme functions of the S-plus package for Windows (beta release 7 of Pinheiro \& Bates). Three linear, mixed-effects models were fit by restricted maximum likelihood (REML method), using AIC (Akaiken information criterion), BIC (Bayesian information criterion), and Log-Lik [log(arithm) likelihood] as criteria and allowing for nested random effects $(26,27)$. The nested structure was defined as sample times within days within subjects. After the nested structure was defined, the random structures were fitted before the fixed structures were added. The fixed effects were added stepwise, using the criteria BIC, Loglik, and AIC to control for the number of variables. This procedure was repeated for the analyses of all 3 hormones.

As independent variables, the hormone baseline, sample time, nature of work ( 3 factor levels of mental, combined mental-physical, and physical), day (4 factor levels of 3 workdays and 1 day off), work characteristics (job demands, job control, and social demands), age, and BMI were entered into the model. So that the models could be fit for the nature of the work and day, the combined mental-physical group and the day off were chosen as the reference levels. Sample time was used as a continuous variable and estimated as a combination of a linear and quadratic term. Dependent variables were the excretion rates of adrenaline, noradrenaline, and cortisol during and after work after log transformation. Random effects were estimated on the subject level per day and the subject level within days. Fixed main effects were

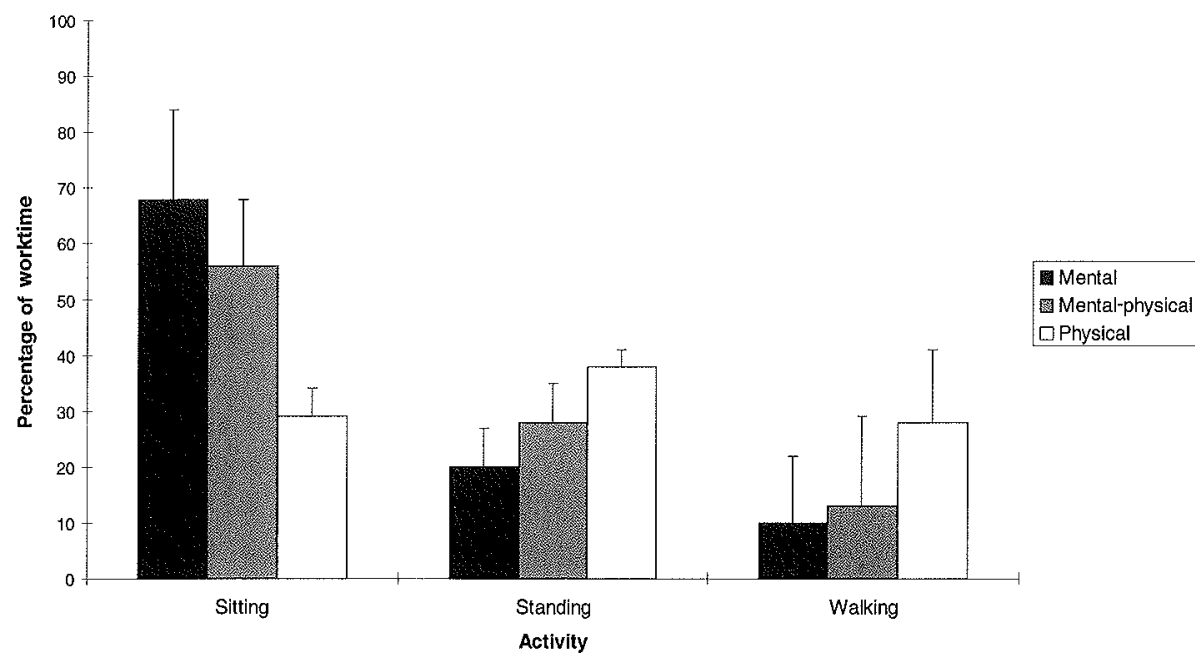

Figure 1. Mean and standard deviation of the percentage of total worktime for the activities sitting, standing, and walking. 
estimated for the hormone baseline, sample time, nature of work, day, work characteristics, age, and BMI. In addition, a fixed interaction effect was estimated for the nature of the work and sample time and its quadratic component (if necessary). Because no unique splitting of the sum of the squares is possible in unbalanced models, no estimation of explained variance could be given.

\section{Results}

\section{Catecholamines and cortisol}

In the appendix, the mean excretion rates of cortisol, adrenaline, and noradrenaline are shown per group of workers for 4 time periods during the workdays and during the days off work as well.

The linear mixed-effects models with the cortisol, adrenaline, and noradrenaline excretion rates as dependent variables are shown in tables $2-4$, respectively. In addition, the predictions from these models as to the level

Table 2. Estimated linear mixed-effects model with age, body mass index (BMI), job demands, job control, social demands, baseline values, sample time, day, nature of work, and the interaction between sample time and the nature of the work as explanatory variables for the excretion of cortisol $(L n) .{ }^{a}$ (REML $=$ restricted maximum likelihood)

\begin{tabular}{|c|c|c|c|c|}
\hline Fixed effects & $\begin{array}{l}\text { Estimated } \\
\text { regression } \\
\text { coefficients }\end{array}$ & $\begin{array}{l}\text { Standard } \\
\text { error }\end{array}$ & t-Values & $P$-values \\
\hline Intercept & 2.384 & 0.433 & 5.500 & 0.00 \\
\hline Age & 0.005 & 0.007 & 0.721 & 0.47 \\
\hline BMI & 0.001 & 0.015 & 0.069 & 0.95 \\
\hline Job demands & -0.011 & 0.004 & -2.550 & 0.01 \\
\hline Job control & 0.003 & 0.004 & 0.705 & 0.48 \\
\hline Social demands & 0.000 & 0.004 & 0.040 & 0.97 \\
\hline Baseline cortisol level & 0.061 & 0.031 & 1.944 & 0.05 \\
\hline Sample time & 0.129 & 0.014 & 8.982 & 0.00 \\
\hline Square of sample time & -0.007 & 0.001 & -12.120 & 0.00 \\
\hline Day off, reference & . & & . & . \\
\hline Workday 1 & 0.124 & 0.053 & 2.346 & 0.02 \\
\hline Workday 2 & 0.089 & 0.053 & 1.686 & 0.09 \\
\hline Workday 3 & 0.067 & 0.058 & 1.152 & 0.25 \\
\hline \multicolumn{5}{|l|}{$\begin{array}{l}\text { Mixed mental and } \\
\text { physical group, reference }\end{array}$} \\
\hline Mental group & 0.542 & 0.226 & 2.395 & 0.02 \\
\hline Physical group & 0.517 & 0.161 & 3.201 & 0.00 \\
\hline Sample time $\times$ mental group & -0.025 & 0.007 & -3.448 & 0.00 \\
\hline Sample time $\times$ physical group & -0.026 & 0.007 & -3.465 & 0.00 \\
\hline Random effects & $\begin{array}{l}\text { Standard } \\
\text { deviation }\end{array}$ & Residual & & \\
\hline \multicolumn{5}{|l|}{ Day - subject } \\
\hline Day off & 0.354 & & & \\
\hline Workday 1 & 0.082 & & & \\
\hline Workday 2 & 0.071 & & & \\
\hline Workday 3 & 0.197 & & & \\
\hline Within day - subject & & 0.675 & & \\
\hline
\end{tabular}

of the nature of the work and the excretion rate during the days are shown in figures $2-4$, respectively. Time was modeled by taking the midpoints of the time periods of the samples (ie, 0300, 0900, 1230, 1530, 1830, and 2130). The standard deviation of the random effects is the variation within days, compared with the 1 st recovery day. The residual, mentioned under random effects, was the total variance per subject within days.

\section{Interpretation of the cortisol model}

The cortisol results (table 2) showed a significant main effect of the nature of the work in comparison with the ambulance workers (ie, the combined mental-physical group); the other groups had higher mean levels. In addition, the interaction between the nature of the work and the sample time revealed a significant effect between the ambulance workers and the 2 other groups. Regarding the other fixed effects, the baseline cortisol level contributed only marginally $(\mathrm{P}=0.05)$ to the model, a finding suggesting higher levels of cortisol when the baseline level was higher. Both estimates of sample time were

Table 3. Estimated linear mixed-effects model with age, body mass index (BMI), job demands, job control, social demands, baseline values, sample time, day, nature of work, and the interaction between sample time and the nature of the work as explanatory variables for the $\mathrm{Ln}$ of the excretion rate of adrenaline. ${ }^{\mathrm{a}}$ (REML = restricted maximum likelihood)

\begin{tabular}{|c|c|c|c|c|}
\hline Fixed effects & $\begin{array}{l}\text { Estimated } \\
\text { regression } \\
\text { coefficients }\end{array}$ & $\begin{array}{l}\text { Standard } \\
\text { error }\end{array}$ & t-Values & P-values \\
\hline Intercept & 0.145 & 0.421 & 0.345 & 0.73 \\
\hline Age & 0.006 & 0.007 & 0.904 & 0.37 \\
\hline $\mathrm{BMI}$ & -0.032 & 0.015 & -2.155 & 0.04 \\
\hline Job demands & -0.004 & 0.004 & -1.002 & 0.32 \\
\hline Job control & 0.001 & 0.004 & 0.244 & 0.81 \\
\hline Social demands & -0.001 & 0.004 & -0.228 & 0.82 \\
\hline Baseline adrenaline level & 0.071 & 0.029 & 2.475 & 0.01 \\
\hline Sample time & 0.350 & 0.016 & 21.736 & 0.00 \\
\hline Square of sample time & -0.013 & 0.001 & -21.066 & 0.00 \\
\hline Day off, reference & & . & & \\
\hline Workday 1 & 0.451 & 0.060 & 7.534 & 0.00 \\
\hline Workday 2 & 0.433 & 0.059 & 7.368 & 0.00 \\
\hline Workday 3 & 0.304 & 0.056 & 5.389 & 0.00 \\
\hline \multicolumn{5}{|l|}{$\begin{array}{l}\text { Mixed mental and } \\
\text { physical group, reference }\end{array}$} \\
\hline Mental group & 0.423 & 0.221 & 1.911 & 0.06 \\
\hline Physical group & 0.527 & 0.155 & 3.392 & 0.00 \\
\hline Sample time $\times$ mental group & -0.023 & 0.007 & -3.512 & 0.00 \\
\hline Sample time $\times$ physical group & -0.039 & 0.007 & -5.603 & 0.00 \\
\hline Random effects & $\begin{array}{l}\text { Standard } \\
\text { deviation }\end{array}$ & Residual & & \\
\hline \multicolumn{5}{|l|}{ Day - subject } \\
\hline Day off & 0.400 & & & \\
\hline Workday 1 & 0.271 & & & \\
\hline Workday 2 & 0.257 & & & \\
\hline Workday 3 & 0.227 & & & \\
\hline Within day - subject & & 0.620 & & \\
\hline
\end{tabular}


highly significant in the model. The estimated regression coefficient of workday 1 differed significantly from the day off work, indicating higher levels of cortisol during the workday. For the 2nd workday, the difference was only marginally significant, and this effect was not found for the 3rd workday, a finding suggesting a decrease in levels from workday 1 to the day off. For the psychosocial work characteristics, only job demands showed a main effect on the excretion of cortisol. The direction of the regression coefficient of job demands indicated lower levels of cortisol when the demands were perceived as higher. Age and BMI did not contribute significantly to the estimated model.

In figure 2, the prediction outcomes for cortisol have been modeled for the 3 groups of workers. The following two points are notable: (i) an interaction during the day was found (the ambulance workers had lower starting levels of cortisol than both of the other groups, but equal levels at the end of the day, a finding suggesting less favorable recovery in this group of workers) and (ii) no notable cumulation in excretion occurred over the 4 days, but there was a trend towards a slow leveling off of the cortisol excretion over the 4 days from the 1 st workday up to the day off. In addition, a post-hoc analysis with Bonferonni correction was performed to test whether differences existed between the 3 groups for the mean baseline measurements and for the excretion rates during the evenings. For cortisol, the baseline level was significantly higher for the ambulance workers than for the other groups (both $\mathrm{P}=0.000$ ), a finding explaining the marginally significant main effect of the baseline values in the model. As could be predicted from figure 3, no differences between the 3 groups were found for the excretion rate levels during the evening.

\section{Interpretation of the adrenaline model}

The adrenaline results (table 3 ) revealed a marginally significant and significant main effect for the nature of the work, a finding indicating higher mean levels of adrenaline in the group of managers and the physical work group in comparison with the ambulance workers. However, the interaction between the nature of the work and the sample time revealed a highly significant effect between the ambulance workers and both the other groups. Regarding other fixed effects, the baseline value for adrenaline contributed significantly $(\mathrm{P}=0.01)$ to the mod$\mathrm{el}$, a finding indicating higher levels of adrenaline when the baseline level was higher. Again, both estimates of sample time were highly significant in the model. The estimated regression coefficient of all the workdays differed significantly from that of the day off, a finding indicating higher adrenaline levels during the workdays. None of the psychosocial work characteristics showed a main effect on the excretion of adrenaline in the model. The BMI contributed significantly to the estimated model, but age did not. The direction of the regression coefficient for the BMI indicated higher mean levels of adrenaline when the BMI was lower.

In figure 3, the prediction outcomes for adrenaline have been modeled for the 3 groups of workers. Although the excretion of the ambulance workers was lower early in the morning, the difference was reversed at midday, and at the end of each day the excretion level had fallen to a level between those of the other groups. This finding suggests that relatively more reactivity was needed during the day in the group of ambulance employees and that recovery was less favorable. This result can be seen in figure 3 by comparing the levels of 0300 with the 2130 levels. In addition, a trend towards slower recovery was found in the evening for the mental group when it was compared with the physical group of workers. As was found for cortisol, a trend towards a slow leveling off of adrenaline excretion was found over the 4 days from the 1 st workday up to the day off. As the main work demands were the same on all the workdays, this finding suggests that less activity was mobilized to cope with the demands

Table 4. Estimated linear mixed-effects model with age, body mass index (BMI), job demands, job control, social demands, baseline values, sample time, day, nature of work, and the interaction between the sample time and the nature of the work as explanatory variables for the $L n$ of the excretion rate of noradrenaline. ${ }^{\text {a }}$ (REML $=$ restricted maximum likelihood)

\begin{tabular}{|c|c|c|c|c|}
\hline Fixed effects & $\begin{array}{l}\text { Estimated } \\
\text { regression } \\
\text { coefficients }\end{array}$ & $\begin{array}{c}\text { Standard } \\
\text { error }\end{array}$ & $\mathrm{t}$-Values & P-values \\
\hline Intercept & 1.534 & 0.356 & 4.315 & 0.00 \\
\hline Age & 0.009 & 0.006 & 1.481 & 0.15 \\
\hline BMI & 0.014 & 0.012 & 1.117 & 0.27 \\
\hline Job demands & 0.002 & 0.003 & 0.516 & 0.61 \\
\hline Job control & $<0.001$ & 0.003 & 0.073 & 0.94 \\
\hline Social demands & -0.002 & 0.003 & -0.580 & 0.56 \\
\hline Baseline noradrenaline & 0.062 & 0.032 & 1.962 & 0.05 \\
\hline Sample time & 0.172 & 0.011 & 15.411 & 0.00 \\
\hline Square of sample time & -0.006 & $<0.001$ & -14.816 & 0.00 \\
\hline Day off, reference & . & . & . & . \\
\hline Workday 1 & 0.172 & 0.052 & 3.323 & 0.00 \\
\hline Workday 2 & 0.189 & 0.056 & 3.396 & 0.00 \\
\hline Workday 3 & 0.157 & 0.059 & 2.660 & 0.01 \\
\hline \multicolumn{5}{|l|}{$\begin{array}{l}\text { Mixed mental and } \\
\text { physical group, reference }\end{array}$} \\
\hline Mental group & 0.127 & 0.183 & 0.694 & 0.49 \\
\hline Physical group & 0.204 & 0.127 & 1.600 & 0.11 \\
\hline Sample time $\times$ mental group & -0.009 & 0.005 & -1.742 & 0.08 \\
\hline Sample time $\times$ physical group & -0.018 & 0.006 & -3.374 & 0.00 \\
\hline Random effects & $\begin{array}{l}\text { Standard } \\
\text { deviation }\end{array}$ & Residual & & \\
\hline \multicolumn{5}{|l|}{ Day - subject } \\
\hline Day off & 0.329 & & & \\
\hline Workday 1 & 0.262 & & & \\
\hline Workday 2 & 0.304 & & & \\
\hline Workday 3 & 0.338 & & & \\
\hline Within day - subject & & 0.496 & & \\
\hline
\end{tabular}

a The dependent variable was noradrenaline; the REML estimation method was used. 


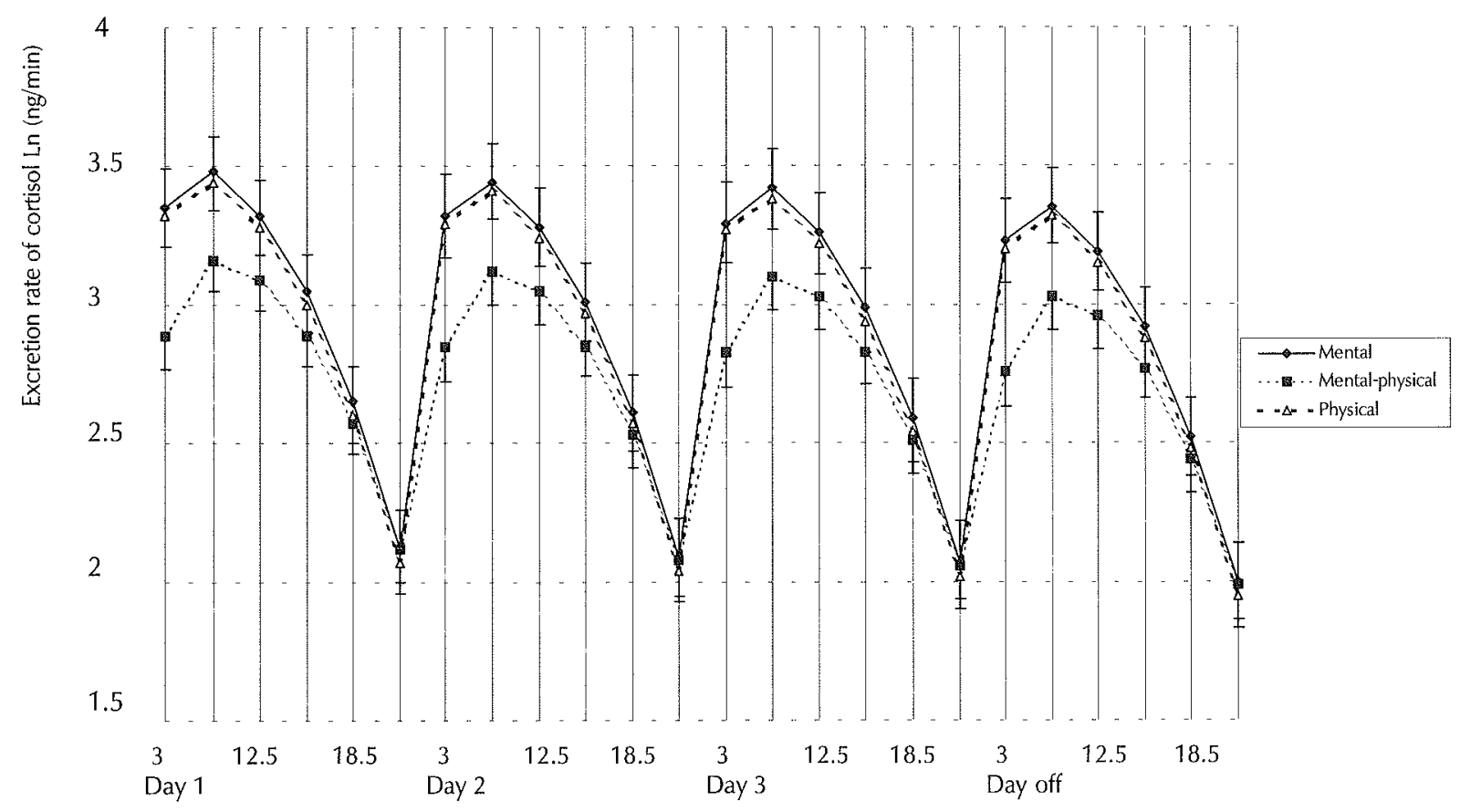

Time of Day

Figure 2. Prediction from all the explanatory variables in table 2 for the $L n$ of the excretion rate of cortisol during 3 workdays and 1 day off in the 3 groups of workers.

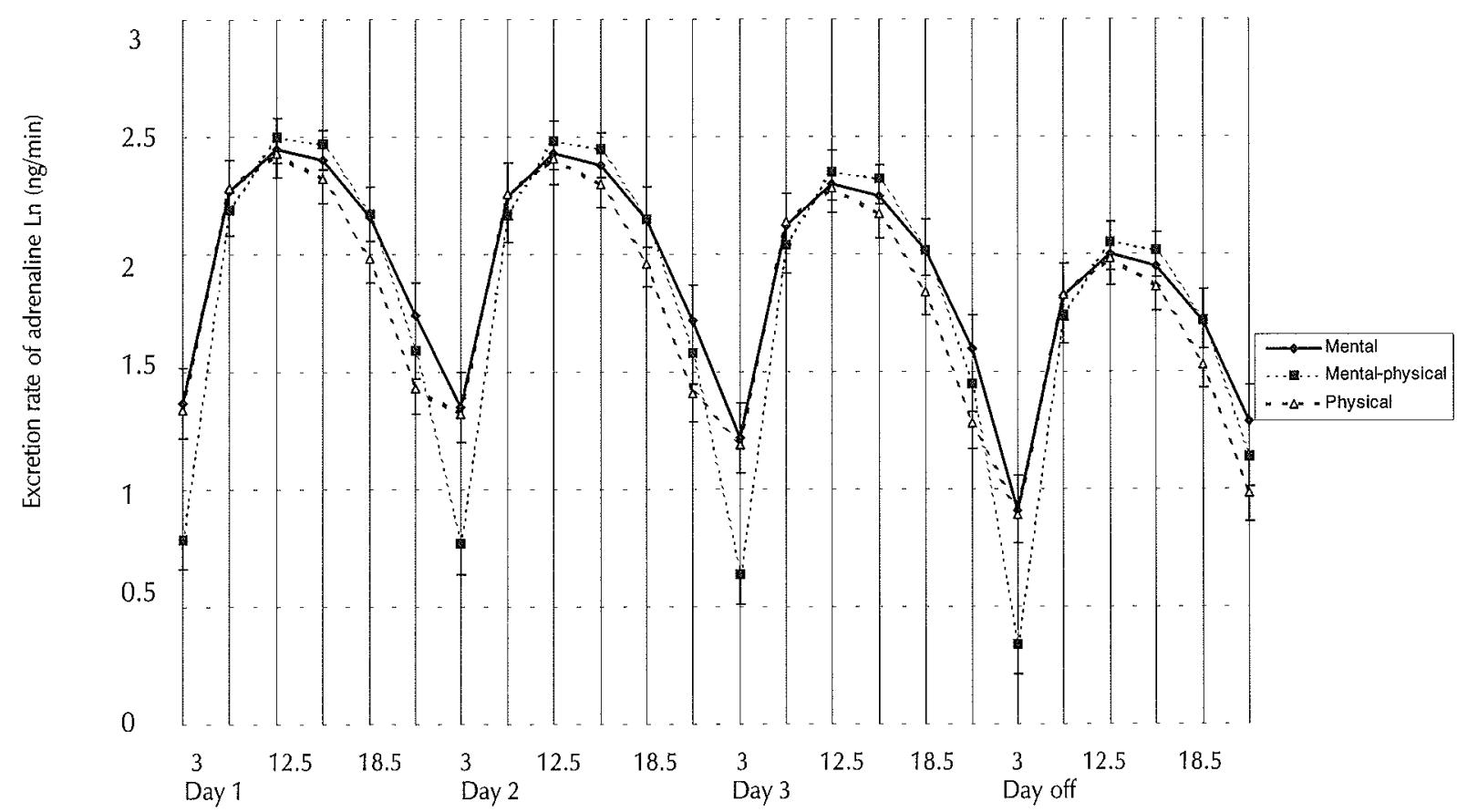

Time of day

Figure 3. Prediction from all the explanatory variables in table 3 for the Ln of the excretion rate of adrenaline during 3 workdays and 1 day off in the 3 groups of workers. 


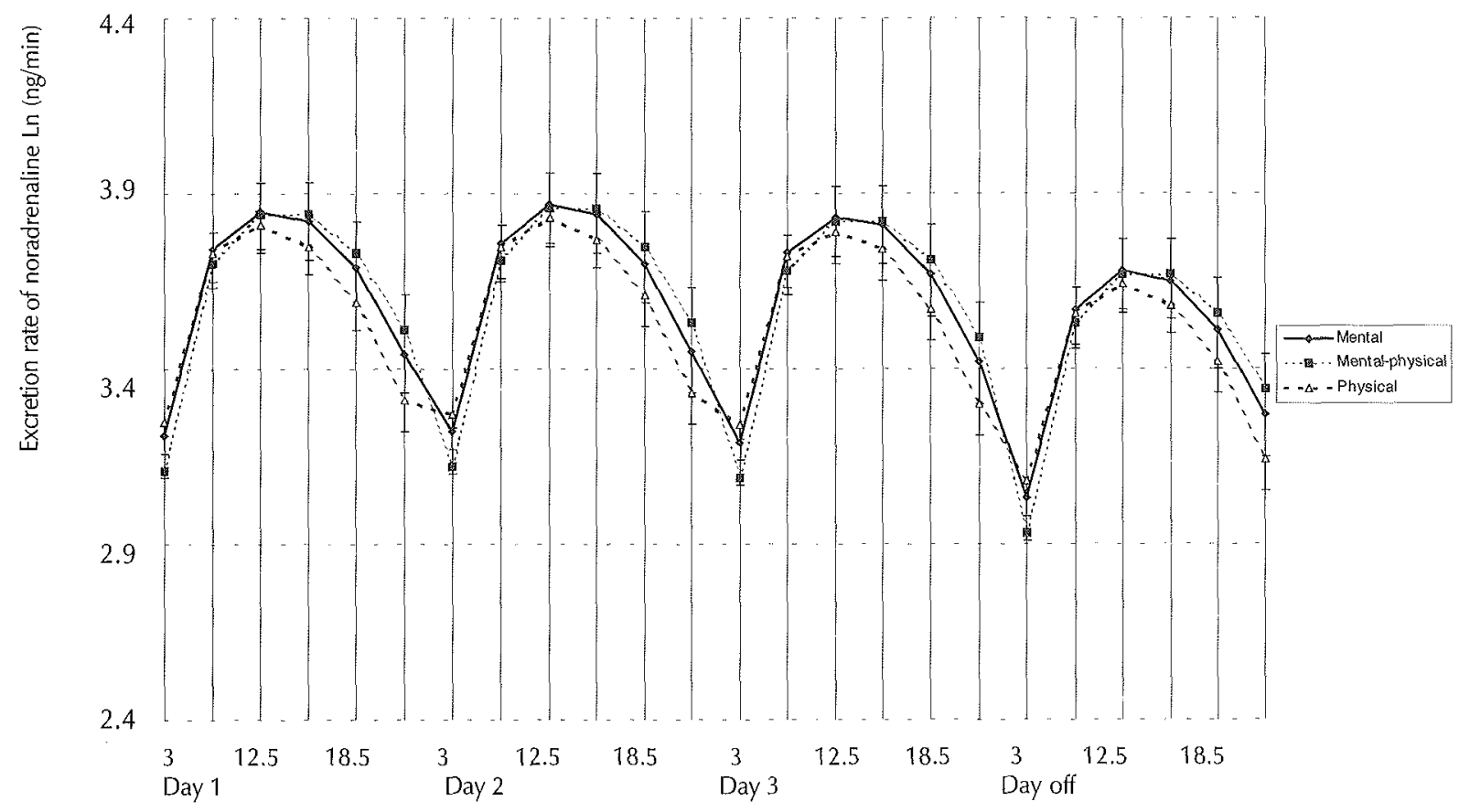

Time of day

Figure 4. Prediction from all the explanatory variables in table 4 for the $L n$ of the excretion rate of noradrenaline during 3 workdays and 1 day off in the 3 groups of workers.

over the workweek. The posthoc analysis for adrenaline revealed that the baseline was significantly higher in the mental-physical group than in the mental group of workers $(\mathrm{P}=0.000)$. No significant differences between the 3 groups were found for the excretion rates during the evenings.

\section{Interpretation of the noradrenaline model}

For the noradrenaline results (table 4), no significant main effect of the nature of the work was found. The interaction between the nature of the work and sample time, however, was marginally significant and significant between the ambulance workers and the managers and physical workers. These effects suggest higher levels of noradrenaline at certain times of the day for the ambulance workers when they are compared with the physical workers. Regarding the other fixed effects, the baseline of noradrenaline contributed only marginally significantly $(\mathrm{P}=0.05)$ to the model, suggesting higher levels of noradrenaline when the baseline level was higher. Once more, both estimates of sample time were highly significant in the model. A significant main effect for all workdays versus the day off was found, a finding indicating higher levels of noradrenaline during the workdays. None of the psychosocial work characteristics showed a main effect on the excretion of noradrenaline in the model. Neither age nor BMI contributed significantly to the estimated model of noradrenaline excretion.
In figure 4, the prediction outcomes for noradrenaline were modeled for the 3 groups of workers. Surprisingly, during part of the day, the excretion of the physical workers was lower. In addition, the evening level, at 2130 , of the physical group had returned to the morning level, at 0300 , on all the days, whereas a trend towards an increase in reactivity was found in the other 2 groups. Once more, a trend towards a slow leveling off in excretion was found over the 4 days from the 1st workday up to the day off. As the main work demands were the same on all the workdays, this finding suggests that less activity was mobilized to cope with the demands over the workweek. The posthoc analysis for noradrenaline revealed that the baseline level was significantly higher for the ambulance workers than for the physical group of workers $(\mathrm{P}=0.01)$. Only marginally significant differences between the 3 groups were found for the absolute excretion rate late in the evenings.

\section{Discussion}

This study examined neuroendocrine reactivity during work and recovery from work for 59 male employees working in jobs with either mainly mental (managers and foremen), combined mental and physical (ambulance workers), or physical (manual flower auction and 
construction workers, and garbage collectors) work demands. What should be emphasized is that the outcomes of the fitted models showed the differences in the relative level of hormone excretion of the 3 groups of workers. A main effect of the nature of the work was found for cortisol and adrenaline excretion, irrespective of levels of the psychosocial work characteristics. The interaction effects between the nature of the work and the time of day, the higher adrenaline reactivity during the day, and the differences in the baseline levels all pointed to possibly more unfavorable effects of the double demands of the work of ambulance workers. For all the workers, the findings suggested a trend towards less activity being mobilized to cope with the same demands over the workweek although this finding might have been caused by habituation to the measurements as well. Regarding the work characteristics, the expected effect of the level of perceived job demands was found to be related to cortisol reactivity and recovery, but not to adrenaline reactivity and recovery. No relation was found between hormone excretion and perceived job control in the models.

The neuroendocrine baseline measurements of the subjects was represented by the 2 nd consecutive day off and was controlled for in the analyses. To a large extent, western worklife is structured in a way that 5 days of work are followed by 2 days off, suggesting that these 2 days give enough time to recover from work-related exertion. Because the time of the examination was chosen at random for each person, the resulting baseline measurement is thought to reflect the subject's mean personal baseline level. Nonetheless, it is still unclear what a fair personal neuroendocrine baseline level actually is, and a choice for measuring more baseline days was made in the study by Meijman et al (7). In the analyses, the day off was used as a reference for comparison with the 3 workdays. Neuroendocrine effects of experimental and occupational studies have been shown up to 24 hours after the test $(14,28-30)$. However, it can possibly be expected that more neuroendocrine effects are found on the workdays than on the day off when work is considered as exposure to demands that influence the neuroendocrine activation level.

The results suggest that, although the combination of mental and physical work had less impact on the mean height of the cortisol excretion when compared with either mental or physical work only, the baseline was higher. Thus the repeated emotional component in the work of the ambulance workers might have contributed to the cortisol effects in this study in accordance with the idea of "wear and tear" from allostatic load (31). Although it is acknowledged that ambulance workers are a rather specific and homogeneous group, it is stated that ambulance workers do represent other jobs with combined mentalphysical and emotional demands, because these kinds of jobs are found mostly in occupations in health care services. No effects of age were found in our study, unlike earlier findings $(2,6,32)$. In contrast with multilevel analyses, however, other analyses made on clustered data may find significant effects due to less valid confidence limits for estimates of the standard errors of the means of the variables (33).

According to the activation theory (34) and the idea of allostasis (31), one might expect more discrepancy between an activation set point and the actual level of activation needed by workers exposed to double demands. However, the cortisol and adrenaline baseline values were higher for the ambulance workers than for the managers and physical group of workers. This finding would indicate even more discrepancy in needed activation in the 2 groups than among the ambulance workers. Such a situation was found for cortisol, but, in contrast, more reactivity in adrenaline during the day was shown for the ambulance workers. Second, the neuroendocrine recovery from work was less favorable for the ambulance workers. According to the cognitive activation theory of stress (CATS) $(35,36)$, this finding also indicates sustained activation in this group of workers. In the more chronic stress perspective, the combination of the higher baseline value but relatively lower reactivity of cortisol for the ambulance workers are in agreement with the functional deficit of the hypothalamus-pituitary-adrenal axis that was found by Demitrack (37) as well. The higher cortisol and adrenaline baseline excretion levels are consistent with the idea of the development of a vicious circle, in which repeated insufficient recovery from work (ie, sustained activation) leads to higher hormone baseline levels. Therefore, the less favorable recovery after work questions the aforementioned possible advantage of double demands in this group of workers as well. A practical consequence of this finding may be that expected positive outcomes of rotations in different types of tasks, from the neuroendocrinological point of view, may turn out to be negative for workers.

At 1st glance, the finding that higher perceived job demands is related to lower cortisol excretion does not appear consistent with the findings described by Lundberg et al (38) and Ursin (35), even more so because no relation was found between job demands and adrenaline or between job control and cortisol. At least 2 explanations can be offered for this finding. First, the scores on the work characteristics job demands, job control, and social demands suggested that the managers had higher job demands, but more control over their work than the other 2 groups. As described by Karasek \& Theorell (39), this occurrence might indicate active rather than high strain jobs for the managers and, therefore, less stress. Second, the mean excretion of cortisol during the day is disproportionately influenced by the peak level values in the morning. Because the peak values of the ambulance workers were lower than in the 2 other groups, the 
predictions may have been influenced. No differences in social demands were found among the 3 groups. The social demand scale was reflected by the sum of 2 scales, namely, the relations with superiors and the relations with colleagues. Exploration of the variability in scores of the original scales found that it was mainly the relation with superiors that differed among the workers, with little variance in scores in the scale regarding the relations with colleagues. In addition, the reliability of the formed scale was found to be moderate only.

The conclusion that the neuroendocrine effects found in our study were probably caused by the main demands of the jobs may have implications for research on work load, as well as on planned intervention at the level of the work organization. It is recommended that, in studies evaluating task enrichment, for example, neuroendocrine measurements of cortisol and adrenaline be included as possible effect parameters before and after the intervention takes place.

\section{Acknowledgments}

This study was carried out under The Netherlands Concerted Research Action "Fatigue at Work" of The Netherlands Organisation of Scientific Research (NWO). We would like to thank the subjects and their companies for their cooperation. We thank Josien Coppoolse, Janneke Brouwer, Paul Kuijer, and Marco Hoozemans for their great help during the data collection, Suzanne van Damme and Sharda Ramlal for their analysis of the cortisol and catecholamine samples, Sijmen Kuiper and Dr Robert Herber for their advice, and Dr Kathleen Rest for her textual contribution.

\section{References}

1. Paoli P. Second European survey on working conditions in the European Union. Dublin: European Foundation for the Improvement of Living and Working Conditions, 1997. No EF9726.

2. Frankenhaeuser M, Lundberg U, Fredrikson M, Melin B, Tuomisto M, Myrsten AL, et al. Stress on and off the job as related to sex and occupational status in white-collar workers. J Organ Behav 1989;10:321-46.

3. Lundberg U. Methods and applications of stress research. Technol Health Care 1995;3:3-9.

4. Gaillard AWK, Wientjes CJE. Evaluation of the work environment: approaches and methods. In: Ullsperger P, Ertel M, Freude E, editors. Berlin: Schriftenreihe der Bundesanstalt fur Arbeitsmedizin, 1996:8-27. Tagungsbericht 11.

5. Ursin H, Baade E, Levine S, editors. Psychobiology of Stress: a study of coping men. New York (NY): Academic Press, 1978.

6. Meijman TF, Mulders HPG, Kompier MAJ, Van Dormolen
M. Individual differences in adrenaline/noradrenaline reactivity and self-perceived health status. Z Gesamte Hyg 1990; $36: 413-4$.

7. Meijman TF, Mulder G, Van Dormolen M, Cremer R. Workload of driving examiners: a psychophysiological field study. In: Kragt H, editor. Enhancing industrial performance. London: Taylor \& Francis, 1992:245-58.

8. Knardahl S, Ursin H. Sustained activation and the pathophysiology of hypertension and coronary heart disease. In: Orlebeke J, Mulder G, Van Doornen L, editors. Psychophysiology of cardiovascular control: models, methods, and data. New York (NY): Plenum Press, 1985:223-37.

9. Ursin H. Personality, activation and somatic health: a new psychosomatic theory. In: Levine S, Ursin H, editors. Coping and health. New York (NY): Plenum Press, 1980:259_79.

10. Rissler A. Stress reactions at work and after work during a period of quantitative overload. Ergonomics 1977;20:57780.

11. Rissler A. Extended periods of challenging demands in high tech work - consequences for efficiency, quality of life and health. Paper presented at the workshop Stress in New Occupations in 1993.

12. Kuiper JI, Van der Beek AJ, Meijman TF. Psychosomatic complaints and unwinding of sympathoadrenal activation after work. Stress Med 1998;14:7-12.

13. Raggatt PTF, Morrissey SA. A field study of stress and fatigue in long-distance bus drivers. Behav Med 1997;23:122 9.

14. Sluiter JK, Van der Beek AJ, Frings-Dresen MHW. Work stress and recovery measured by urinary catecholamines and cortisol excretion in long distance coach drivers. Occup Environ Med 1998;55:407-13.

15. Sluiter JK, Frings-Dresen MHW, Meijman TF, Van der Beek AJ. Recovery from different natures of work measured by catecholamines and cortisol: a systematic literature overview. Occup Environ Med 2000;57:298-315.

16. De Zwart BCH, Broersen JPJ, Van der Beek AJ, FringsDresen MHW, Van Dijk FJH. Occupational classification according to work demands: an evaluation study. Int J Occup Med Environ Health 1997;10:283-95.

17. Karasek R, Baker D, Marxer F, Ahlbom A, Theorell T. Job decision latitude, job demands, and cardiovascular disease: a prospective study of Swedish men. Am J Public Health 1981; $71: 694-705$.

18. Toomingas A, Theorell T, Michélsen H, Nordemar R, Stockholm MUSIC I Study Group. Associations between self-rated psychosocial work conditions and musculoskeletal symptoms and signs. Scand J Work Environ Health 1997;23:130_-9.

19. Theorell T, Tsutsumi A, Hallquist J, Reuterwall C, Hogstedt $C$, Fredlund $P$, et al. Decision latitude, job strain, and myocardial infarction: a study of working men in Stockholm. Am J Public Health 1998;88:382-8.

20. Frankenhaeuser M, Lundberg U, Forsman L. Dissociation between sympathetic-adrenal and pituitary-adrenal responses to an achievement situation characterized by high controllability: comparison between type $\mathrm{A}$ and type $\mathrm{B}$ males and females. Biol Psychol 1980;10:79—91.

21. Härenstam AB, Theorell TPG. Work conditions and urinary excretion of catecholamines - a study of prison staff in Sweden. Scand J Work Environ Health 1988;14:257-64.

22. Doncevic S, Theorell T, Scalia-Tomba G. The psychosocial work environment of district nurses in Sweden. Work Stress $1988 ; 2: 341-51$.

23. Theorell T, Ahlberg-Hulten G, Sigala F, Perski A, Soderholm 
M, Kallner A, et al. A psychosocial and biomedical comparison between men in six contrasting service occupations. Work Stress 1990;4(1):51-63.

24. Van Veldhoven MJPM. Psychosocial job demands and workstress [Psychosociale arbeidsbelasting en werkstress; thesis]. Lisse (The Netherlands): Swets \& Zeitlinger, 1996.

25. Frings-Dresen MHW, Kuijer PPFM. The TRAC-system: an observation method for analysing work demands at the workplace. Saf Sci 1995;21:163-5.

26. Laird Nm, Ware JH. Random-effects models for longitudinal data. Biometrics 1982;38:963-74.

27. Venables WN, Ripley BD. Modern applied statistics with Splus. 2nd ed. Berlin: Springer-Verlag, 1997.

28. Nieman DC, Berk LS, Simpson-Westerberg M, Arabitz K, Youngberg S, Tan SA, et al. Effects of long-endurance running on immune system parameters and lymphocyte function in experienced marathoners. Int J Sports Med 1989;10:317 23.

29. Berk LS, Nieman DC, Youngberg WS, Arabitz K, SimpsonWesterberg M, Lee JW, et al. The effect of long endurance running on natural killer cells in marathoners. Med Sci Sports Exerc 1990;22:207-12.

30. Heitkamp H-C, Huber W, Scheib K. Beta-Endorphin and adrenocorticotrophin after incremental exercise and marathon running - female responses. Eur J Appl Physiol 1996;72:417-24

31. McEwen BS. Protective and damaging effects of stress mediators. New Eng J Med 1998;338:171—9.

32. Lundberg $U$. Influence of paid and unpaid work on psycho- physiological stress responses of men and women. Occup Health Psychol 1996;1:117-30.

33. Reijneveld SA, Boshuizen HC. Multilevel analyse van hierarchische gegevens: methode en toepassing op buurtverschillen in gezondheid en rookgedrag [Multilevel analyses of hierarchical data regarding socioeconomic differences]. Tijdschr Soc Gezondheid 1999;77:96-104.

34. Ursin H, Knardahl S. Personality factors, neuroendocrine response patterns, and cardiovascular pathology. In: Orlebeke J, Mulder G, Van Doornen L, editors. Psychophysiology of cardiovascular control. New York (NY): Plenum Press, 1985: 715-31.

35. Ursin H. The psychology in psychoneuroendocrinology. Psychoneuroendocrinology 1998;23:555-70.

36. Eriksen HR, Olff M, Murison R, Ursin H. The time dimension in stress responses: relevance for survival and health. Psychol Res 1999;85:39-50.

37. Demitrack MA. Neuroendocrine correlates of chronic fatigue syndrome: a brief review. J Psychiatr Res 1997;31(1):69-82.

38. Lundberg U, Granqvist M, Hansson T, Magnusson M, Wallin L. Psychological and physiological stress responses during repetitive work at an assembly line. Work Stress 1989;3:14353.

39. Karasek RA, Theorell T. Healthy work: stress, productivity, and the reconstruction of working life. New York (NY): Basic Books, Inc: 1990:31-82.

Received for publication: 15 June 1999

\section{Appendix}

Urinary excretion rates of cortisol, adrenaline, and noradrenaline - mean values and standard deviations per day and time period and per group of workers ( $\mid=$ mental group, $\|=$ mixed mental and physical group, $|I|=$ physical group).

\begin{tabular}{|c|c|c|c|c|c|c|c|c|c|c|c|c|c|c|c|c|c|c|}
\hline \multirow[t]{3}{*}{ Day } & \multicolumn{6}{|c|}{ Cortisol (ng/min) } & \multicolumn{6}{|c|}{ Adrenaline (ng/min) } & \multicolumn{6}{|c|}{ Noradrenaline (ng/min) } \\
\hline & \multicolumn{2}{|c|}{ Group I } & \multicolumn{2}{|c|}{ Group II } & \multicolumn{2}{|c|}{ Group III } & \multicolumn{2}{|c|}{ Group 1} & \multicolumn{2}{|c|}{ Group II } & \multicolumn{2}{|c|}{ Group III } & \multicolumn{2}{|c|}{ Group I } & \multicolumn{2}{|c|}{ Group II } & \multicolumn{2}{|c|}{ Group III } \\
\hline & Mean & $\mathrm{SD}$ & Mean & $\mathrm{SD}$ & Mean & SD & Mean & $\mathrm{SD}$ & Mean & $\mathrm{SD}$ & Mean & $\mathrm{SD}$ & Mean & SD & Mean & $\mathrm{SD}$ & Mean & SD \\
\hline \multicolumn{19}{|l|}{ Workday 1} \\
\hline Before 0700 & 35.7 & 34 & 31.0 & 34 & 44.3 & 39 & 4.2 & 3 & 4.1 & 6 & 5.5 & 5 & 29.9 & 16 & 30.6 & 27 & 27.7 & 19 \\
\hline $0700-1700$ & 31.6 & 21 & 34.8 & 25 & 35.7 & 20 & 13.2 & 8 & 13.8 & 8 & 11.5 & 6 & 48.6 & 18 & 50.3 & 22 & 52.5 & 22 \\
\hline $1700-2000$ & 11.9 & 12 & 14.5 & 14 & 18.9 & 20 & 10.4 & 6 & 9.0 & 5 & 8.0 & 6 & 41.2 & 16 & 43.7 & 20 & 37.4 & 21 \\
\hline $2000-2300$ & 8.9 & 7 & 10.9 & 7 & 8.9 & 6 & 7.1 & 7 & 6.4 & 4 & 5.0 & 5 & 38.5 & 19 & 38.3 & 24 & 28.1 & 16 \\
\hline \multicolumn{19}{|l|}{ Workday 2} \\
\hline Before 0700 & 26.7 & 18 & 18.9 & 17 & 43.0 & 36 & 4.6 & 4 & 2.1 & 2 & 4.9 & 5 & 30.4 & 19 & 22.1 & 13 & 28.0 & 18 \\
\hline $0700-1700$ & 27.9 & 16 & 34.5 & 22 & 31.0 & 17 & 12.4 & 7 & 13.7 & 6 & 11.5 & 6 & 49.3 & 20 & 52.0 & 24 & 54.7 & 24 \\
\hline $1700-2000$ & 12.4 & 14 & 22.2 & 31 & 16.2 & 11 & 9.5 & 8 & 9.3 & 5 & 8.2 & 6 & 36.8 & 14 & 44.1 & 20 & 36.0 & 19 \\
\hline $2000-2300$ & 10.7 & 7 & 10.0 & 6 & 13.6 & 15 & 9.4 & 7 & 7.8 & 8 & 5.2 & 3 & 49.1 & 22 & 41.5 & 23 & 36.4 & 21 \\
\hline \multicolumn{19}{|l|}{ Workday 3} \\
\hline Before 0700 & 37.6 & 40 & 31.1 & 30 & 44.7 & 37 & 5.0 & 5 & 3.0 & 3 & 4.8 & 3 & 33.9 & 21 & 24.4 & 16 & 30.4 & 20 \\
\hline $0700-1700$ & 22.9 & 14 & 31.4 & 17 & 32.6 & 24 & 11.7 & 8 & 11.9 & 5 & 10.8 & 5 & 45.8 & 18 & 49.8 & 19 & 56.1 & 22 \\
\hline $1700-2000$ & 11.9 & 10 & 19.2 & 21 & 17.4 & 13 & 7.2 & 7 & 7.7 & 3 & 9.0 & 6 & 36.6 & 19 & 42.7 & 14 & 46.0 & 26 \\
\hline $2000-2300$ & 8.1 & 7 & 17.8 & 25 & 10.5 & 11 & 5.6 & 7 & 5.1 & 2 & 4.2 & 2 & 36.9 & 17 & 36.0 & 14 & 32.0 & 17 \\
\hline \multicolumn{19}{|l|}{ Day off } \\
\hline Before 0700 & 22.7 & 14 & 24.9 & 14 & 27.0 & 20 & 2.3 & 2 & 1.8 & 1 & 2.2 & 2 & 21.9 & 9 & 21.0 & 9 & 20.2 & 10 \\
\hline $0700-1700$ & 24.1 & 18 & 26.1 & 16 & 29.7 & 20 & 8.4 & 7 & 9.2 & 6 & 7.9 & 5 & 43.0 & 17 & 43.3 & 19 & 38.4 & 21 \\
\hline $1700-2000$ & 12.1 & 10 & 19.0 & 15 & 16.1 & 8 & 7.5 & 6 & 7.1 & 4 & 8.3 & 10 & 38.7 & 15 & 43.0 & 19 & 33.9 & 21 \\
\hline $2000-2300$ & 10.8 & 12 & 11.7 & 10 & 10.6 & 8 & 6.2 & 6 & 4.8 & 3 & 3.8 & 2 & 38.0 & 17 & 31.7 & 14 & 31.2 & 16 \\
\hline \multicolumn{19}{|l|}{ Baseline day } \\
\hline Before 0700 & 18.5 & 11 & 26.2 & 17 & 24.3 & 16 & 1.6 & 1 & 1.7 & 1 & 1.9 & 1 & 17.1 & 7 & 22.3 & 11 & 20.2 & 11 \\
\hline $0700-1700$ & 22.5 & 16 & 27.0 & 16 & 28.1 & 17 & 6.6 & 4 & 7.9 & 5 & 6.4 & 4 & 36.0 & 16 & 37.9 & 18 & 35.6 & 20 \\
\hline $1700-2000$ & 10.6 & 7 & 12.5 & 9 & 15.4 & 15 & 7.0 & 8 & 6.7 & 4 & 7.0 & 5 & 36.3 & 17 & 37.9 & 15 & 31.4 & 14 \\
\hline $2000-2300$ & 6.2 & 3 & 12.8 & 9 & 6.7 & 3 & 3.5 & 3 & 4.2 & 2 & 4.2 & 3 & 30.0 & 11 & 32.6 & 14 & 28.0 & 15 \\
\hline
\end{tabular}

